\title{
Proyecciones macroeconómicas para 2008 \\ Sin muchas expectativas de crecimiento y con un complicado panorama inflacionario
}

Durante 2008, el Banco

Central de Chile deberá

hacer honor a su política antiinflacionaria y subir las tasas de interés. No hay otra manera de mantener la meta de inflación en torno al tres por ciento. $Y$ en rigor, tampoco deberíamos solazarnos con un crecimiento como el de años anteriores. Las señales del último trimestre de 2007 parecen indicar que

el crecimiento va a andar en torno al cinco o 4,5 por ciento. El profesor Carlos José García, de la facultad de Economía y Negocios de la Universidad Alberto Hurtado, analizó estos y otros temas para un 2008 que se viene complicado.

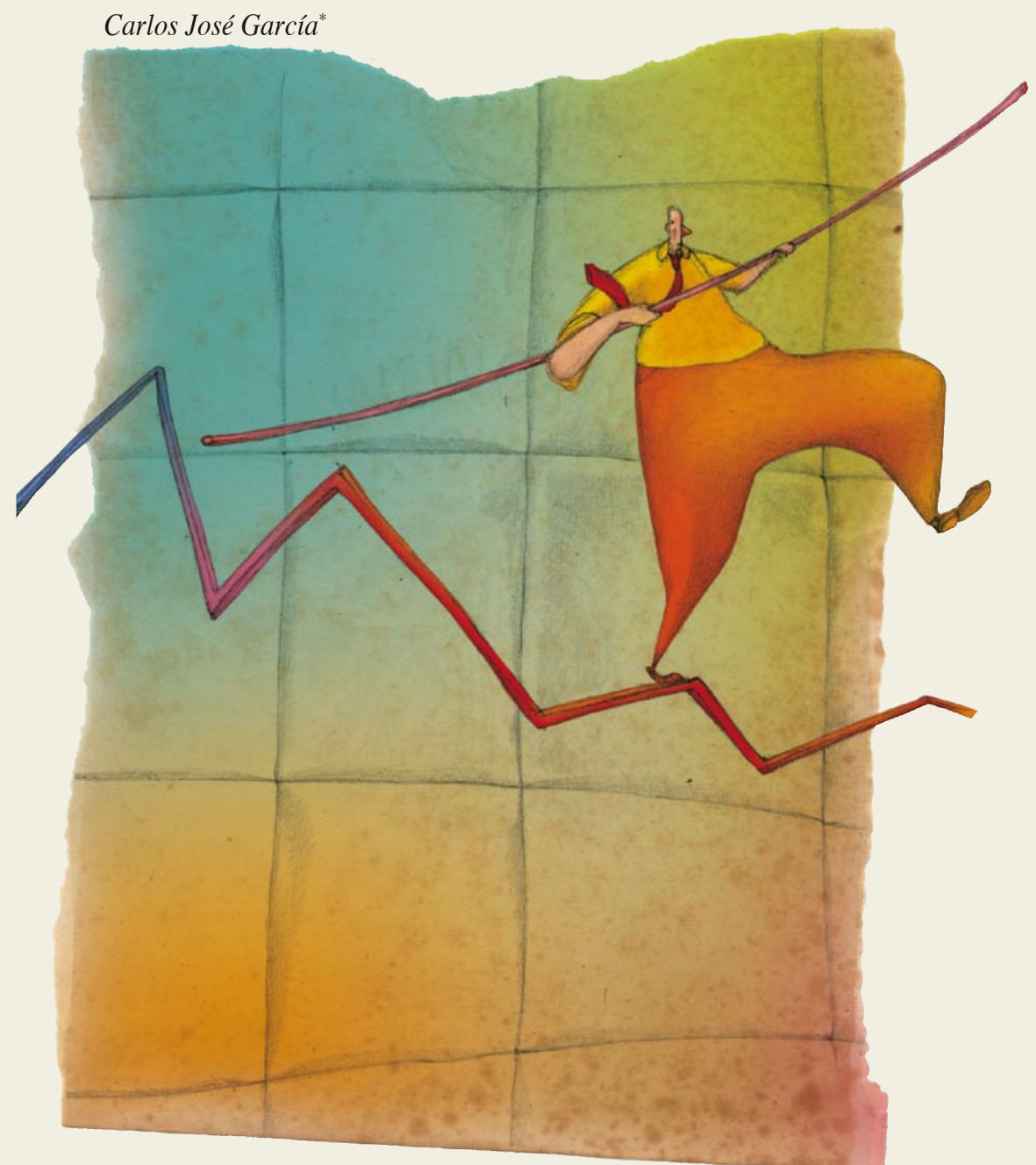

Los indicadores recientes en la inflación y en el crecimiento demuestran que la economía chilena enfrentará en 2008 un ambiente bastante más incierto que el pronosticado para el 2007. Son muchas las preguntas sobre la evolución futura de la economía que se hacen en los mercados financieros y los sectores productivos.

¿Volverá la inflación al 3,0\%? ¿Se está desacelerando la economía o la reducción del crecimiento significa sólo volver a crecer a tasas más normales? ¿Qué nos indican las fluctuaciones del dólar? ¿Cuál será su nivel en 2008? ¿Subirán las tasas de interés? ¿Cuáles serán las consecuencias de la crisis de los mercados de hipotecas en los Estados Unidos sobre la economía mundial y sobre la de Chile? ¿Cómo se verán sectores específicos afectados por todos estos desarrollos?

En esta edición del Observatorio Económico de la Facultad de Economía y Negocios de la Universidad Alberto Hurtado discutiremos desarrollos recientes de la economía chilena que podrían dar pistas concretas de los escenarios más probables para el 
2008, y veremos los posibles riesgos que podrían complicar ese desempeño.

La evidencia indica que algunos de los shocks que están detrás de la alta inflación persistirán en 2008, por tanto es difícil que la inflación vuelva a 3\% (el rango meta) sin que el Banco Central suba la tasa de interés de política monetaria. El aumento a $6 \%$ de la tasa de interés en diciembre de 2007 es una señal en ese sentido. En efecto: es impresentable que la inflación esté fuera del rango meta por dos años seguidos. Si así ocurriera, se pondría en entredicho la credibilidad de la meta de inflación y con ello la política antiinflacionaria de los últimos veinte años. A este panorama se suma el hecho de que el nuevo presidente del Banco Central, José de Gregorio, deberá reafirmar el compromiso del Banco Central contra la inflación, lo que genera presión extra sobre la política monetaria.

Por otra parte, el crecimiento de la economía, más que sufrir una desaceleración, estaría volviendo a tasas más realistas que fluctúan entre $4,5 \%$ y $5 \%$ en un escenario positivo.

El tipo de cambio en el 2008 seguirá fluctuando fuerte. En este momento hay dos fuerzas que tensionan al precio del dólar en direcciones opuestas. La desaceleración en los Estados Unidos, que reduce el precio del dólar en los mercados inter- nacionales, y las peores expectativas de crecimiento en la economía chilena, que incitan a que este precio suba en Chile. El escenario más probable es que el dólar siga bajo durante 2008, y que tenga un repunte a finales de es año; si es que consideramos un escenario positivo para la economía internacional.

El menor crecimiento y el dólar bajo tendrán importantes efectos sobre sectores productivos específicos. Esto, sin considerar la incertidumbre en los mercados internacionales por la crisis de las hipotecas: si sus efectos se traducen en un escenario de menor crecimiento mundial, podrían significar una merma en los precios de nuestros productos de exportación.

\section{Inflación: el año que debemos vol- ver al tres por ciento.}

Las cifras del IPC en los últimos meses han constituido noticias negativas. La inflación mensual en noviembre fue de $0,8 \%$, una de las más altas en los últimos años (Figura 1). De hecho, se espera que la inflación acumulada en el año sobrepase el $7,5 \%$, muy por encima del $4 \%$, el techo de la banda establecida por el Banco Centra de Chile para su meta de inflación. ¿Pero hay realmente evidencia que el Banco Central está perdiendo el control sobre la inflación?

Figura 1: ¿Inflación descontrolada?: evolución de la inflación el 2007. Variación respecto a igual período del año anterior, \%

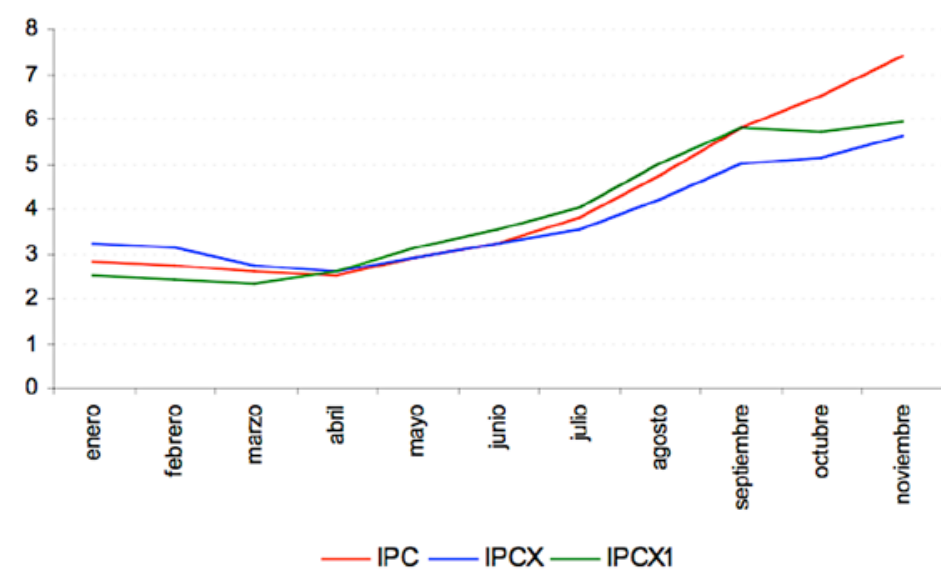

Fuente: INE y BCCh

Detrás de la alta inflación están los shocks de oferta en precios de commodities, en particular el precio de los cereales, los lácteos y el del petróleo, que ha rozado la barrera sicológica de los 100 dólares por barril. La Figura 2 muestra la evolución de algunos precios específicos que confirma lo anterior. El precio de los alimentos ha alcanzado niveles de crecimiento en doce meses de hasta $16 \%$ (Figura 2, Alimentación). Como es natural que ocurra, se han activado los mecanismos de indización elevando el costo de los arriendos y el pago de dividendos (Figura 2, Vivienda). Por otra parte, los precios del sector transporte también han comenzado a aumentar empujados por los precios del petróleo (Figura 2, Transporte).

Por tanto una pregunta relevante para definir el escenario futuro de la inflación es qué tan persistentes son estos shocks de oferta. Primero, puesto que una parte de los aumentos de los precios (frutas y verduras) fue causada por las fuertes heladas de la temporada de invierno, estas presiones ya están comenzando a desaparecer con el inicio de la temporada de verano. Segundo, el incremento en el precio de los lácteos y combustibles responde al aumento internacional de estos productos, en parte explicada por restricciones de oferta (sequías en Australia o la limitada capacidad instalada para la extracción de petróleo), pero principalmente por la fuerte demanda internacional por productos básicos de todo tipo. En este conjunto debemos incluir productos tan variados como el cobre y el precio del trigo. Así, la persistencia en los aumentos de estos precios dependerá en parte importante de si continúa la expansión de las economías o si estas se ven afectadas por la crisis hipotecaria en los Estados Unidos. Hasta el momento, los precios de los commodities siguen altos, en especial el del petróleo. Proyecciones de la Agencia Internacional de Energía de los Estados Unidos lo sitúan en los 80 dólares por barril para 2008. En consecuencia, el escenario para la inflación es negativo: se espera que el precio de los commodities se mantenga alto por lo menos en los próximos seis meses. 
Figura 2: Los precios que marcaron la inflación el 2007 Variación respecto a igual período del año anterior, \%

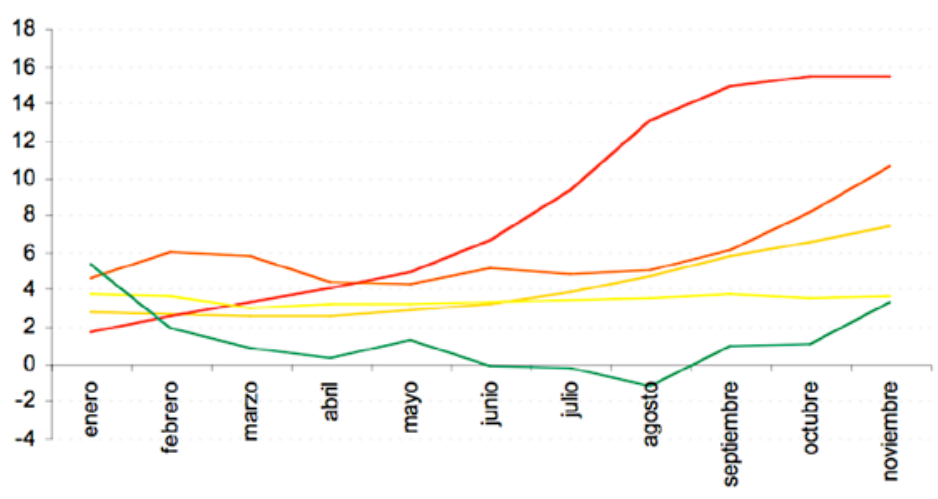

IPC Agregado —-Alimentos — Vivienda — Educación — Transporte

Fuente: INE

Figura 3: Expectativas inflación para diciembre de 2007 y 2008

Variación respecto a igual período del año anterior, \%

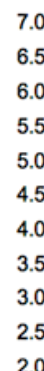

7.0
6.5
6.0
5.5
5.0
4.5
4.0
3.5
3.0
2.5
2.0

$$
\text { ธิ }
$$

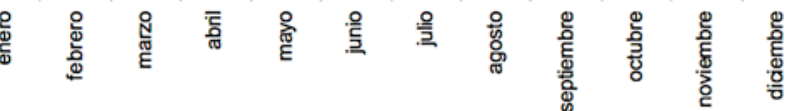

—Dic-07 — Dic-08

Fuente: BCCh

Sin embargo, aun queda responder si la naturaleza "externa" de los shocks significa que hay que esperar que los efectos sobre la inflación se disipen solos, sin la necesidad de la intervención del Banco Central. Sin duda que la respuesta es "no".
Si el Banco Central definió una de meta de $3 \%$ para la inflación dentro de un rango de $+/-1 \%$, la inflación no puede estar dos años consecutivos fuera del rango, esperando pacientemente que los shocks externos de precios desaparezcan. En la

\section{EXCELENTES PROFESIONALES, $\gamma^{\mathrm{a}}$ En Galidad $/ \mathrm{J}^{\mathrm{a} \text { Profesores }}$ grandes personas IOEEnte a con Doctorado

Estudia Ingeniería Comercial e Ingeniería Comercial para Profesionales

medida que estos shocks persisten, los bancos centrales deben implementar políticas más contractivas para asegurar que otros precios ayuden a reducir la inflación. Un elemento clave dentro de este proceso es afectar las expectativas de inflación para desincentivar los aumentos en esos precios y así mantener la credibilidad en la política monetaria. Como se observa en la Figura 3, las expectativas inflacionarias para diciembre de 2008 han comenzado a subir moderadamente, reflejando no sólo un empeoramiento del escenario inflacionario, sino también el desafío que está enfrentado el Banco Central en esta materia.

\section{Crecimiento: ¿es el año de la des- aceleración o sólo creceremos a tasas más realistas?}

La economía se expandió a una tasa de 6\% hasta mediados de 2007 (Figura 4), sin embargo, en el tercer trimestre la economía creció sólo un $4,1 \%$, lo que significó un ajuste importante en las expectativas de crecimiento del mercado. Estas estaban fijadas en casi $6 \%$ a principio del año y cayeron a menos de 5,3\% en diciembre. Un desglose de la información sobre el tercer trimestre indica que la economía en general registra un sesgo a un crecimiento por debajo del $5 \%$. La industria, principal sector de la economía, con una participación de $16 \%$ sobre el PIB, creció sólo $0,1 \%$. Por otra parte, sectores importantes como el comercio, la minería y servicios financieros, que contabilizan el $30 \%$ del PIB, crecieron a tasas cercanas al $4 \%$. La agricultura y el sector energía, en cambio, registraron importantes retrocesos, con caídas de $1,1 \%$ y $20 \%$, aunque su participación en conjunto en el PIB es de sólo 5\%. Solamente la construcción y los servicios financieros mostraron tasas de expansión por sobre el $6,5 \%$, con una participación conjunta sobre el PIB de $23 \%$.

¿Es esta tasa de crecimiento del PIB del tercer trimestre un indicador de una desaceleración transitoria de la economía?¿O es una demostración de que el crecimiento de tendencia de la economía no da para más de 5\%? Con los antecedentes que se disponen, la economía crecería por debajo de 5\%. Primero, varios indicadores parciales señalan que la economía se estaría desacelerando. Por una parte, el Indicador Mensual de Actividad Económica (IMACEC) ha venido registrando en los últimos 
meses tasas cercanas al 4,2\% (Figura 5.A). Por otra parte, han empeorado las expectativas sobre el crecimiento de la economía (Figura 5.B) ${ }^{1}$.

Por el lado de la demanda agregada, el consumo se expandió el tercer trimestre en $6,5 \%$, después de registrar tasas por sobre $7 \%$ en los trimestres anteriores. En efecto, la expansión del consumo se estaría suavizando por la estabilización de los ingresos del trabajo. Los salarios reales han dejado de crecer, afectados en parte por la mayor inflación ${ }^{2}$, y la tasa de desempleo se ha estabilizado en torno al 7,4\% (Figuras 5.C y 5.D). Además, las peores expectativas sobre el futuro de la economía estarían afectando la dinámica de la inversión, que creció 9,5\% el tercer trimestre después del auspicioso $14,6 \%$ del segundo.

¿Realmente estamos entrando en una etapa de menos crecimiento? La figura 4 muestra, además del crecimiento del PIB, el crecimiento del PIB potencial a través de dos metodologías. Una representa el promedio del panel de expertos del Ministerio de Hacienda y otro es el estudio de Fuentes, Gredig y Larrain (2007) ${ }^{3}$. Según estos antecedentes, el crecimiento potencial de la economía, es decir, aquel que no produce presiones inflacionarias estaría entre $4 \%$ y $5 \%$. Desde esta perspectiva, la economía estaría retornando sólo a una tasa de crecimiento de tendencia, aunque insuficiente por algunos motivos. Primero: no es una tasa suficiente para que la economía chilena alcance en el mediano plazo estándares de vida niveles de economía desarrollada. Segundo: en el corto plazo una cifra de crecimiento "optimista" de $5 \%$ deja a la economía a merced de elementos claves que podrían llevarla fácilmente a un desempeño peor de lo pronosticado: las restricciones energéticas (especialmente en el invierno y los altos precios del petróleo), la inestabilidad del escenario internacional, y una sobrereacción de la política monetaria para controlar la inflación. Cualquiera de estos elementos desarrollados negativamente significará que la tasa de crecimiento para 2008 se situará más cerca del $4 \%$ que del $5 \%$.

\section{Figura 4: ¿Para donde va la economía? PIB trimestral vs. PIB potencial Variación respecto a igual período del año anterior, \%}

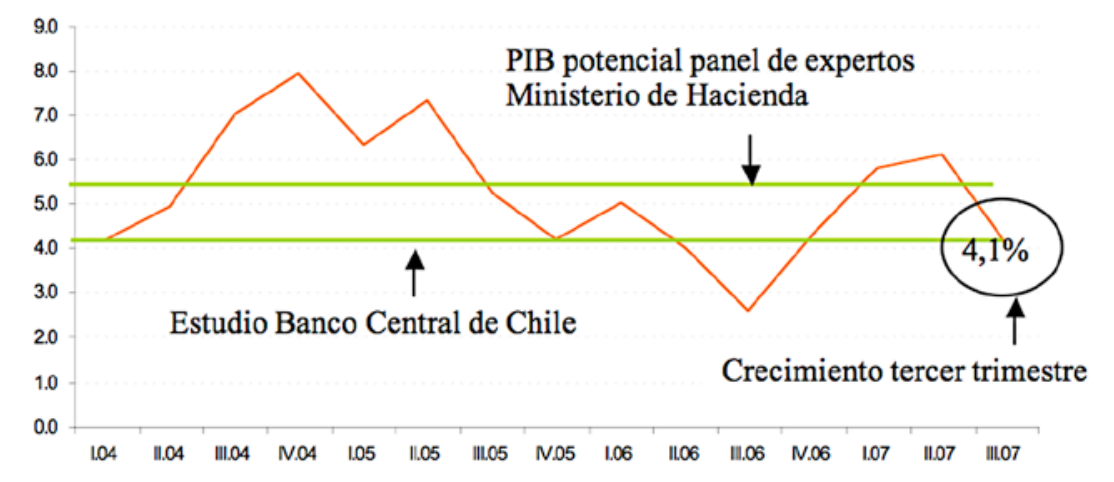

Fuente: BCCh y elaboración propia

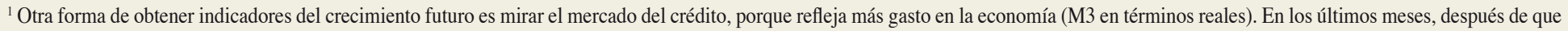
el M3 creció fuerte, ha comenzado a reducir su tasa de expansión en 12 meses, lo que anticiparía una menor dinámica en la actividad económica en los próximos meses.

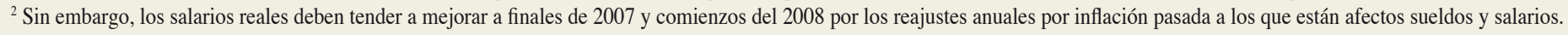

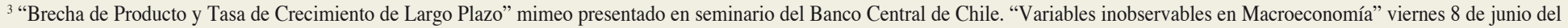
2007.
} 
llevaron el dólar nuevamente cerca de los 500 pesos/dólar.

La evolución del dólar durante 2008 es bastante incierta. Si la crisis de los deudores hipotecarios en los Estados Unidos se traduce finalmente en un menor crecimiento mundial, es probable que el peso tienda a depreciase con respecto al dólar. Esto por los menores precios de nuestras principales exportaciones debido a una demanda mundial más débil. Sin embargo, este escenario supone que la política monetaria y fiscal en los Estados Unidos será incapaz de frenar una recesión severa en ese país. Este escenario, si bien no es completamente descartarble, no es muy probable.

Por otra parte, si el mundo se desacopla del ciclo económico en los Estados Unidos, el dólar seguirá bajando por debajo de los 500 pesos/dólar. Sin embargo, tampoco tiene muchas posibilidades de ocurrencia porque la economía americana es un im- portante socio comercial de Europa, Japón y en especial de China.

Por último está la posibilidad que aunque los Estados Unidos se desaceleren fuertemente, se recuperen por la efectividad de la política monetaria de la Reserva Federal en normalizar los mercados financieros y por los paquetes de salvataje que el gobierno americano está anunciando para alivianar la carga financiera de deudores hipotecarios. En ese caso el dólar tendrá una depreciación pequeña en el corto plazo, y repuntará en el mediano plazo en todos los mercados. Todo esto hace pensar que el dólar bajo se mantendría durante buena parte de 2008 y que sólo hacia fines de ese año el precio podría volver a niveles similares a los observados antes de la crisis de las hipotecas (520-530 pesos/dólar y con un sesgo al alza por las menores expectativas de crecimiento en Chile). La duda en este caso será qué tan fuerte caerá la economía americana y si esto puede tener un impacto suficiente para afectar negativamente chilena.

Figura: 5 Indicadores de Actividad durante el 2007 Nota: * Variación respecto a igual período del año anterior, \%
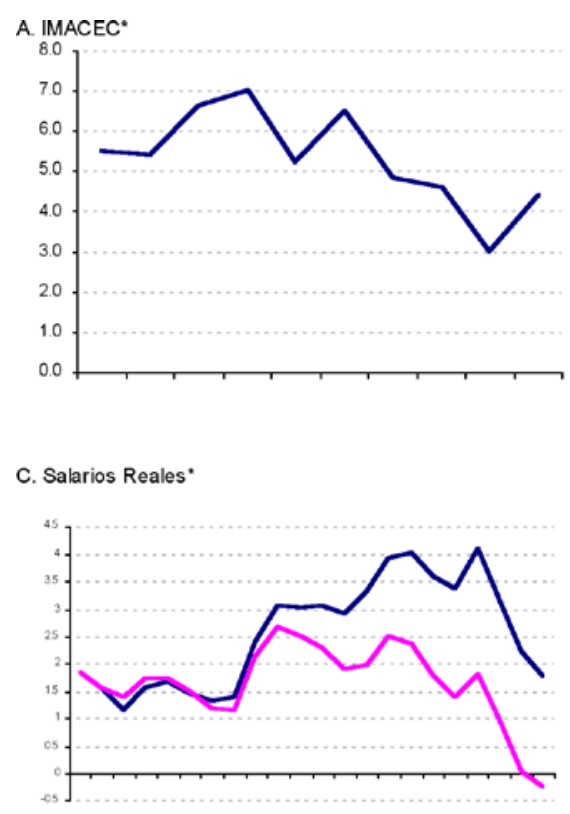

—Indice General de Remuneraciones Costo de la Mano de Obra

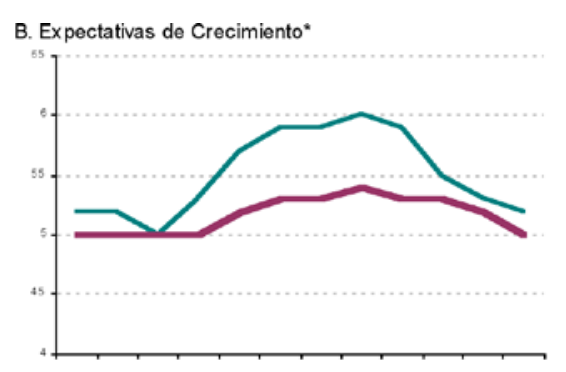

$-2007-2008$

D. Tasa de Desempleo

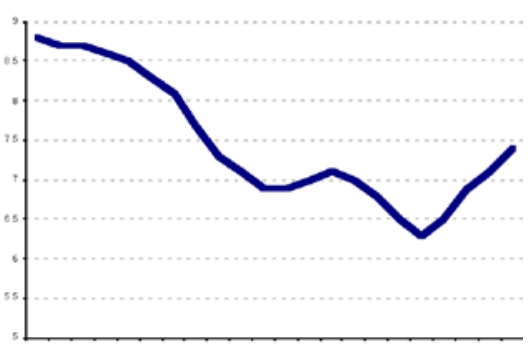

Fuente: BCCh 


\section{Observatorio Económico}

tario excesivo para reafirmar credibilidad puede frenar aún más el crecimiento en la economía. En este escenario el dólar será más volátil: las mayores tasas tenderán a hacer caer su precio, pero las menores expectativas de crecimiento lo fortalecerán.

El aumento de la tasa de política monetaria se ilustra en el ejercicio contra factual ${ }^{4}$ de calcular la tasa de política monetaria (TPM) necesaria para asegurar un crecimiento de $4,5 \%$ promedio del IMACEC para 2008 y una inflación de $3 \%$ a diciembre de 2008 (Figura 7). La tasa de política monetaria, en este ejercicio estilizado, debería por lo menos subir en 100 puntos bases. Es importante aclarar que este no es un ejercicio de proyecciones puesto que fija arbitrariamente las trayectorias de la inflación y el crecimiento para el 2008, pero ilustra que los objetivos de inflación de $3 \%$ y un crecimiento moderado, en torno al 4,5\%, son compatibles sólo con tasas más altas.

Figura 6: evolución de las paridades

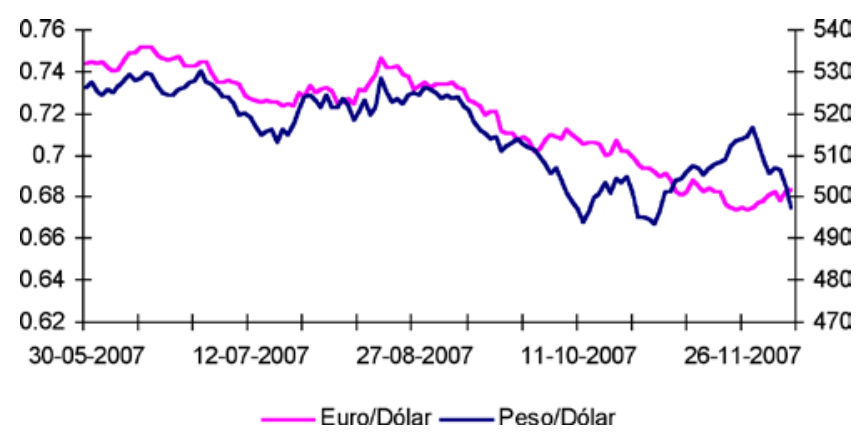

Fuente: BCCh

Figura 7: TPM necesaria para un crecimiento de 4,5\% y una inflación de 3\% en diciembre 2008
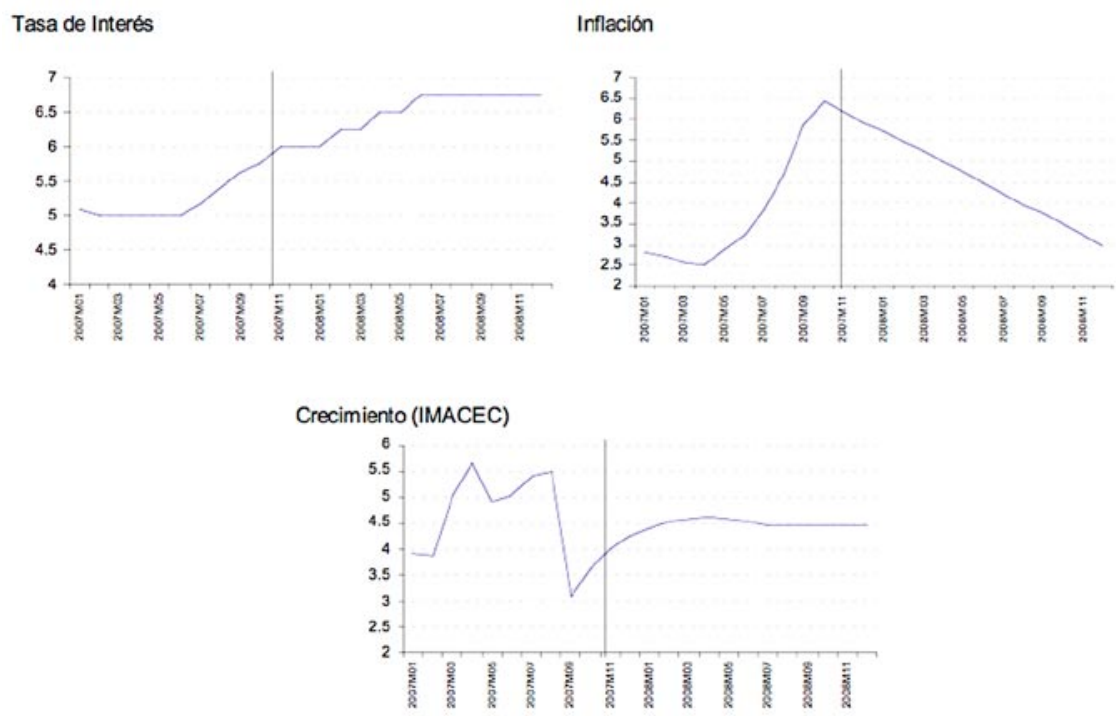

Fuente: elaboración propia

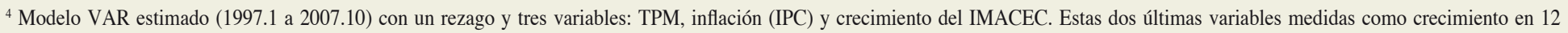
meses.
} 


\section{Proyecciones y conclusiones}

Lo más probable es que el menor crecimiento esperado para 2007 sea también la antesala de un menor crecimiento para 2008. La desaceleración que se observó en el último trimestre de 2007 no parece ser un evento particular. La economía debería estar cercana a un crecimiento de entre 4,5\% y $5 \%$, sobre todo si la crisis hipotecaria en los Estados Unidos no tiene un impacto importante sobre el desempeño de la economía mundial. En caso contrario, la economía chilena podría mostrar incluso tasas de crecimiento menores, cercanas a $4 \%$.

La persistencia de los shocks de precios de commodities ha comenzado a perpetuar niveles altos de inflación a través de los mecanismos de indización existenten en la economía (salarios, tarifas reguladas y contratos). Es difícil que la inflación vuelva a la meta de $3 \%$ si el Banco Central no sube las tasas de interés durante el primer semestre del 2008. Además el nuevo presidente del Banco Central, José de Gregorio, deberá seguir manteniendo alta la credibilidad ganada por el Banco en su lucha contra la inflación. Esto, sin duda, pondrá más presión sobre la política monetaria. Así, un excesivo aumento de la tasa de interés, puede llevar a la economía a crecer por debajo de $4,5 \%$.

El tipo de cambio seguirá mostrando fuertes fluctuaciones, especialmente durante el primer semestre. En este momento hay diferentes fuerzas que tensionan el precio del dólar en direcciones opuestas. La desaceleración en los Estados Unidos está provocando que el dólar caiga en los mercados internacionales, con lo cual establece una tendencia para el tipo de cambio en Chile. Sin embargo, las peores expectativas de crecimiento en la economía chilena presionan a la alza este precio. El escenario más probable es que el dólar siga bajo durante el 2008, y que repunte al final en la medida que la Reserva Federal de los Estados Unidos y el gobierno de ese país puedan resolver exitosamente la crisis de la hipotecas.

El impacto del entorno macro sobre sectores específicos se resume en la Tabla 2. Suponiendo un crecimiento base entre
4,5\%-5\%, con un sesgo hacia al límite inferior, los sectores en general son afectados por un menor crecimiento esperado para el 2008 respecto del 2007 y por mayores tasas de interés. Muchos de los sectores también son afectados por un dólar bajo. En algunos casos, como las exportaciones no mineras, el menor crecimiento de los Estados Unidos es también un factor relevante. En cambio, en el sector minero, la diversificación de las exportaciones (especialmente hacia China) permite proyectar un año similar a 2007, aunque con riesgos por un menor precio del cobre si se concreta un escenario internacional más negativo.

\begin{tabular}{lccr}
\hline \multicolumn{3}{c}{ Tabla 1 } & \\
\hline Proyecciones Escenario Internacional \\
\hline Variables & 2006 & 2007 & 2008 \\
\hline Crecimiento $*$ & & & \\
EE.UU. & 2.9 & 1.9 & $1.9(2.8)$ \\
Zona Euro & 2.8 & 2.5 & $2.1(2.3)$ \\
Japón & 2.2 & 2.0 & $1.7(1.9)$ \\
China & 11.1 & 11.5 & $10.0(9.5)$ \\
Latinoamérica & 5.4 & 4.9 & $4.2(4.2)$ \\
Precios & & & \\
Cobre** & 1.6 & 3.2 & 3.1 \\
Petróleo*** & 66.0 & 70.5 & 80.0 \\
\hline
\end{tabular}

Nota: proyecciones en abril de 2007 entre paréntesis.

Fuente: FMI *, Cochilco ** y Energy Information Administration***

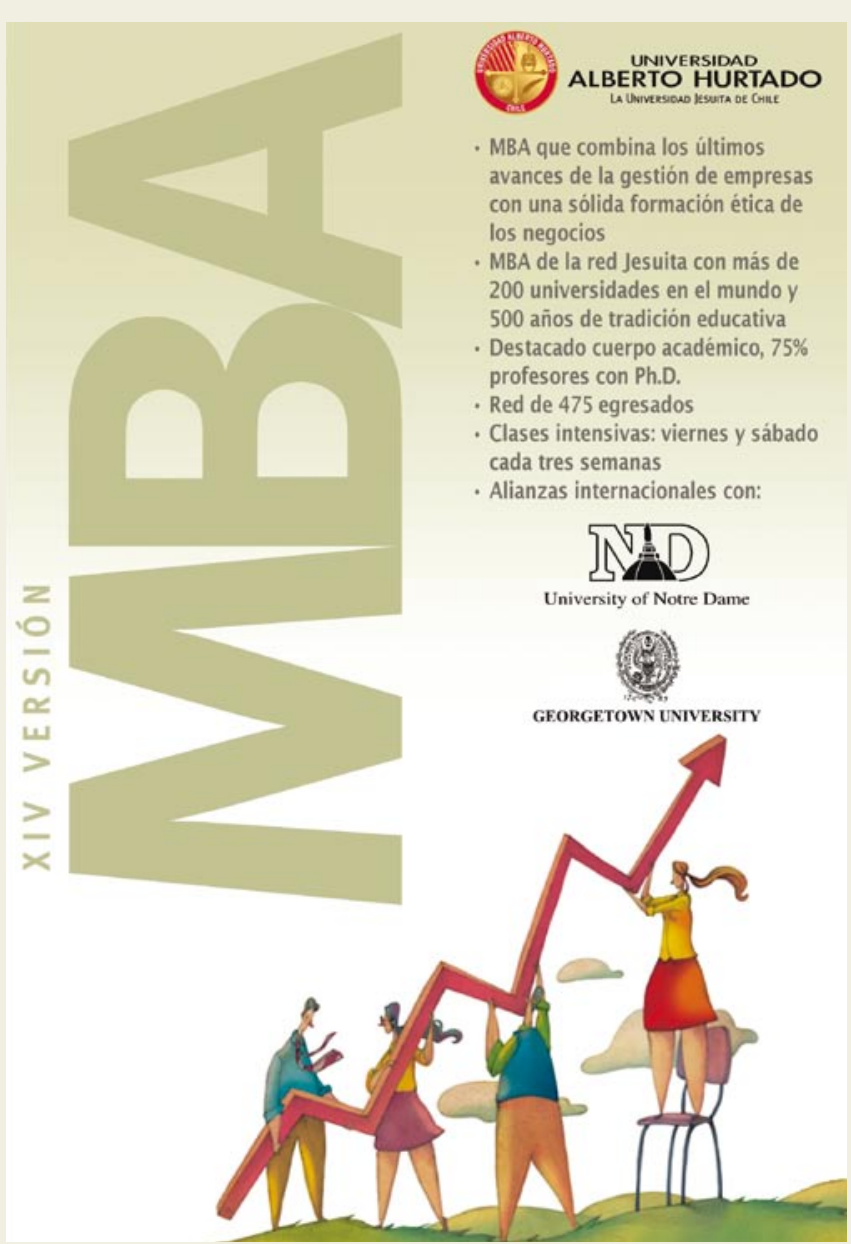




\section{Observatorio Económico}
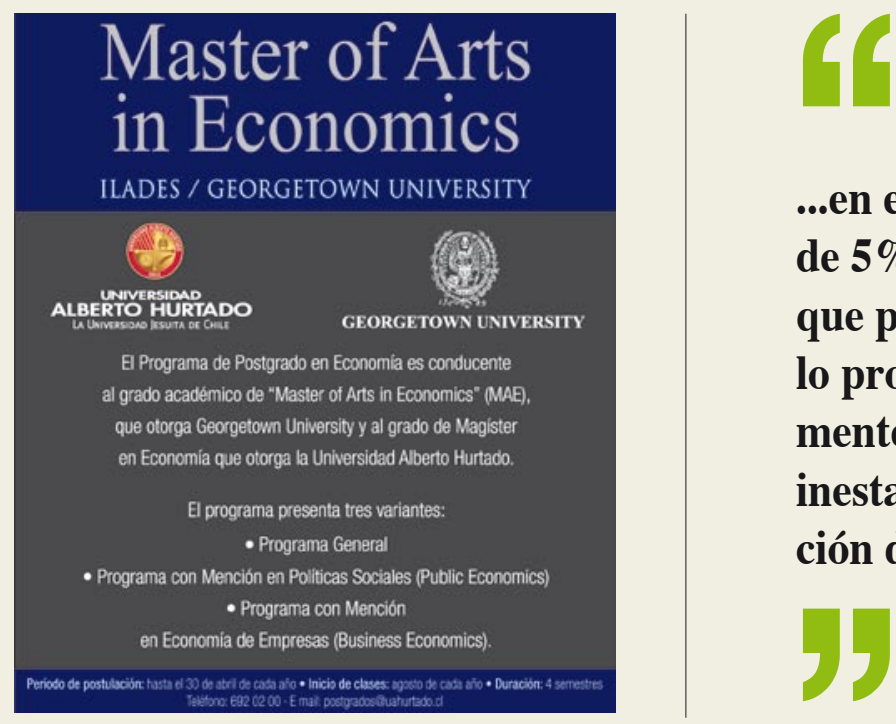

...en el corto plazo una cifra de crecimiento "optimista" de $5 \%$ deja a la economía a merced de elementos claves que podrían llevarla fácilmente a un desempeño peor de lo pronosticado: las restricciones energéticas (especialmente en el invierno y los altos precios del petróleo), la inestabilidad del escenario internacional, y una sobrereacción de la política monetaria para controlar la inflación.

Tabla 2: Impacto Macro en Sectores Seleccionados

Escenario de crecimiento $(4,5 \%-5 \%)$

\begin{tabular}{|c|c|c|c|}
\hline Sectores & Factores Positivos & Factores Negativos & 2007 vs. 2008 \\
\hline Comercio & Dólar bajo; & Menos crecimiento. Tasa de interés más altas & Similar \\
\hline Construcción & & Menos crecimiento. Tasa de interés más altas & Peor \\
\hline Industria & & Menos crecimiento. Tasa de interés más altas; Dólar bajo & Peor \\
\hline Exportador: & & & \\
\hline Minero Cobre & $\begin{array}{l}\text { China mantiene su crecimiento. } \\
\text { Precio del cobre (¿?) } \\
\text { China y otros países }\end{array}$ & Dólar bajo & Similar \\
\hline Minero no Cobre & mantienen su crecimiento & Menos crecimiento en EE.UU. Dólar bajo & Similar \\
\hline Frutícola & $\begin{array}{l}\text { Asia y Europa mantienen } \\
\text { su crecimiento }\end{array}$ & Menos crecimiento en EE.UU. Dólar bajo & Peor \\
\hline Forestal & & Menos crecimiento en EE.UU. Dólar bajo & Mixtos \\
\hline Vino & & Menos crecimiento en EE.UU. Dólar bajo & Peor \\
\hline Salmones & Japón mantienen su crecimiento & Menos crecimiento en EE.UU. Dólar bajo & Mixtos \\
\hline Otros Sectores: & & & \\
\hline $\begin{array}{l}\text { Bienes de Consumo } \\
\text { Durable }\end{array}$ & Dólar bajo; & Menos crecimiento. Tasa de interés más altas & Peor \\
\hline $\begin{array}{l}\text { Inversión de Maquinarias } \\
\text { y Equipo }\end{array}$ & & Menos crecimiento. Tasa de interés más altas & Peor \\
\hline Agrícola & Precios internacionales altos & Dólar bajo; & Mixtos \\
\hline
\end{tabular}

Fuente: elaboración propia 